\title{
ANALISIS KELAYAKAN INVESTASI USAHA KECIL WARNET (Studi Pada Warnet Bulian City Net Muara Bulian)
}

\author{
Sumantri \\ STIE Graha Karya Muara Bulian
}

\begin{abstract}
Market Prospects At this time the need for information society is greatly improved, to meet this need required adequate facilities in order to send and receive good information, especially in telecommunication services. Warnet as a business that provides computer rental services to access the internet. Because the cafe business around Islamic High School is only 5 (five), then the researchers only do 1 sample. Assessments that have been done above with various methods of business feasibility study analysis then the business cafe "Bulian City Net" is feasible to run by looking at considerations of business feasibility study analysis method In full capital return is only required operational for 1 year 9 months 2 days, then the capital Rp.100.000.000 invested will return 100\%. Net Cash Flow reach $R p$ 54.700.000 per peride per year then it is feasible to run Multy Game business. This Net. Because Net Present Value is positive, that is comparison between PV Process and PV investment.
\end{abstract}

Keywords: Analysis, Investment, Business

\section{PENDAHULUAN}

Prospek Pasar pada saat ini kebutuhan masyarakat akan informasi sangat meningkat, untuk memenuhi kebutuhan ini diperlukan sarana-sarana yang memadai dalam rangka pengiriman dan penerimaan informasi yang baik terutama dalam pelayanan jasa telekomunikasi. Untuk melihat kelayakan usaha tersebut dapat diketahui dari berbagai aspek-aspek yang harus diperhatikan oleh pemilik usaha tersebut, kita lihat satu persatu aspek-aspek tersebut yang pertama aspek pasar, apabila pasar atau konsumen yang akan menikmati produk jasa ini tidak begitu banyak berarti dilihat dari aspek pasar usaha ini tidak layak, yang kedua aspek teknis apabila tidak ada unsur-unsur teknis yang mendukung jalannya usaha ini tidak dapat berjalan dengan maksimal, aspek keuangan apakah modal yang diperlukan memenuhi target dan sumber-sumber dana yang ditaksirkan, aspek manajemen siapa yang melakukan masing-masing aspek tersebut, aspek hukum bagaimana bentuk legalitas perusahaan, apakah mempunyai izin usaha, aspek sosial bagaimana pengaruhnya kepada masyarakat sekitar proyek.

Manfaat Ekonomi Untuk mendapatkan klien atau pelanggan baru dan menciptakan basis klien tidak selalu dapat diperoleh dengan mudah. Perjuangan untuk memperoleh pelanggan harus melalui berbagai usaha termasuk menganalisa pasar secara hati-hati, pemasaran produk dan mempunyai uji coba basis pelanggan. Internet merupakan salah satu alternatif wadah yang tepat untuk dijadikan sebagai tempat untuk basis pertemuan jutaan orang di seluruh dunia. Dengan demikian untuk mendapatkan pelanggan baru lebih mudah dengan adanya kelompok yang besar di Iternet tersebut. 


\section{Tinjauan Pustaka}

Investasi

Menururut Wikipedia Ensiklopedia bebas bahwa Berdasarkan teori ekonomi, investasi berarti pembelian (dan produksi) dari modal barang yang tidak dikonsumsi tetapi digunakan untuk produksi yang akan datang (barang produksi). Contohnya membangun rel kereta api atau pabrik. Investasi adalah suatu komponen dari PDB dengan rumus $\mathrm{PDB}=\mathrm{C}+\mathrm{I}+\mathrm{G}+(\mathrm{X}-\mathrm{M})$. Fungsi investasi pada aspek tersebut dibagi pada investasi non-residential (seperti pabrik dan mesin) dan investasi residential (rumah baru). Investasi adalah suatu fungsi pendapatan dan tingkat bunga, dilihat dengan kaitannya. $I=(Y, i)$. Suatu pertambahan pada pendapatan akan mendorong investasi yang lebih besar, di mana tingkat bunga yang lebih tinggi akan menurunkan minat untuk investasi sebagaimana hal tersebut akan lebih mahal dibandingkan dengan meminjam uang.

Walaupun jika suatu perusahaan lain memilih untuk menggunakan dananya sendiri untuk investasi, tingkat bunga menunjukkan suatu biaya kesempatan dari investasi dana tersebut daripada meminjamkan untuk mendapatkan bunga.

\section{Komunikasi}

Dewasa ini, komunikasi antara dua individu atau lebih sering dilakukan melalui perangkat teknologi komunikasi, baik perangkat keras (hardware) maupun perangkat lunak (software), sebagai media penyampain pesan atau informasi dari pengirim (sender) kepada penerima pesan (receiver). Adalah komputer, PDA dan perangkat mobile yang menjadi media komunikasi dan media informasi sekarang ini. Warnet sebagai usaha yang memberikan jasa rental komputer untuk mengakses internet.

Secara harfiah, Internet (kependekan dari interconnected-networking) ialah sistem global dari seluruh jaringan komputer yang saling terhubung menggunakan standar Internet Protocol Suite (TCP/IP) untuk melayani miliaran pengguna di seluruh dunia. Manakala Internet (huruf 'I' besar) ialah sistem komputer umum, yang berhubung secara global dan menggunakan TCP/IP sebagai protokol pertukaran paket (packet switching communication protocol). Rangkaian internet yang terbesar dinamakan Internet. Cara menghubungkan rangkaian dengan kaedah ini dinamakan internetworking.

Jumlah pengguna Internet yang besar dan semakin berkembang, telah mewujudkan budaya Internet. Internet juga mempunyai pengaruh yang besar atas ilmu, dan pandangan dunia. Dengan hanya berpandukan mesin pencari seperti Google, pengguna di seluruh dunia mempunyai akses Internet yang mudah atas bermacam-macam informasi. Dibanding dengan buku dan perpustakaan, Internet melambangkan penyebaran(decentralization) / pengetahuan (knowledge) informasi dan data secara ekstrem. Perkembangan Internet juga telah memengaruhi perkembangan ekonomi. Berbagai transaksi jual beli yang sebelumnya hanya bisa dilakukan dengan cara tatap muka (dan sebagian sangat kecil melalui pos atau telepon), kini sangat mudah dan sering dilakukan melalui Internet. Transaksi melalui Internet ini dikenal dengan nama e-commerce.

Terdapat kebimbangan masyarakat tentang Internet yang berpuncak pada beberapa bahan kontroversi di dalamnya. Pelanggaran hak cipta, pornografi, pencurian identitas, dan pernyataan kebencian (hate speech), adalah biasa dan sulit dijaga. Hingga tahun 2007, Indonesia masih belum memiliki Cyberlaw, 
padahal draft akademis RUU Cyberlaw sudah dibahas sejak tahun 2000 oleh Ditjen Postel dan Deperindag. UU yang masih ada kaitannya dengan teknologi informasi dan telekomunikasi adalah UU Telekomunikasi tahun 1999. Internet juga disalahkan oleh sebagian orang karena dianggap menjadi sebab kematian. Brandon Vedas meninggal dunia akibat pemakaian narkotik yang melampaui batas dengan semangat dari teman-teman chatting IRCnya. Shawn Woolley bunuh diri karena ketagihan dengan permainan online, Everquest. Brandes ditikam bunuh, dan dimakan oleh Armin Meiwes setelah menjawab iklan dalam Internet.

Di Indonesia, seperti negara berkembang dimana akses Internet dan penetrasi PC sudah cukup tinggi dengan didukungnya Internet murah dan netbook murah, hanya saja di Indonesia operator kurang fair dalam menentukan harga dan bahkan ada salah satu operator yang sengaja membuat "perangkap jebakan" agar pengguna Internet tersebut membayar lebih mahal. Lainnya sekitar $42 \%$ dari akses Internet melalui fasilitas Public Internet Access seperti warnet, cybercafe, hotspot dll. Tempat umum lainnya yang sering dipakai untuk akses Internet adalah di kampus dan di kantor. Sama seperti halnya sebuah komunitas, Internet juga mempunyai tata tertib tertentu, yang dikenal dengan nama Nettiquette atau dalam bahasa Indonesia dikenal dengan istilah netiket. Untuk di Indonesia selain tata tertib sosial di Internet juga diberlakukan peraturan (UU ITE).

\section{METODE}

Metode penelitian adalah cara ilmiah untuk mengumpulkan data dengan tujuan dan kegunaan tertentu. Ciri ilmiah adalah: rasional, empiris, dan sistematis. Sedangkan syarat data untuk penelitian, adalah sebagai berikut:

- Valid (derajat ketepatan)

Data valid diperoleh dengan cara; menggunakan instrumen penelitian yang valid; mengunakan sumber data yang tepat dan cukup jumlahnya; menggunakan metode pengumpulan data yang tepat/benar; dan reliabel (derajat konsistensi/keajegan).

Data reliabel diperoleh dengan cara; menggunakan instrumen penelitian yang reliabel; dan objektif (interpersonal agreement)

Manusia dari kodratnya dibekali dengan hasrat ingin tahu. Dengan adanya hasrat ingin tahu, selalu timbul berbagai macam pertanyaan. Oleh karena itu manusia selalu berusaha mencari jawaban atas pertanyaan tersebut. Disamping itu dengan menggunakan akal budinya manusia mengembangkan pengetahuan yang berguna untuk kelangsungan hidupnya.

Dalam penelitian ini peneliti menggunakan Alat Penelti yang terdiri dari Aliran Kas Bersih (Net Cash Flow) dan Nilai Bersih Sekarang (Net Present Value).

\section{Aliran Kas Bersih ( Net Cash Flow)}

Arus Kas atau Cash Flow adalah gambaran mengenai jumlah uang yang masuk (cash in flow) dan jumlah uang yang keluar (cash out flow). Arus kas atau cash flow dalam keuangan keluarga sedikit berbeda dengan cash flow dalam perusahaan. Dalam keuangan keluarga, cash flow yang dimaksud adalah cash flow sesuai dengan cash basis. Sebagai informasi, dalam bisnis atau perusahaan dikenal cash basis dan accrual basis.

- Cash Flow yang positif berarti: penghasilan Anda lebih besar dari pada pengeluaran. 
- Cash Flow yang negatif berarti: penghasilan Anda lebih kecil dari pada pengeluaran.

Salah satu permasalahan yang dihadapi oleh keluarga atau individu adalah permasalahan mengurus keuangan, alias kesalahan dalam mengurus cash flow.

\section{Nilai Bersih Sekarang (Net Present Value)}

NPV (Net Present Value) merupakan selisih antara pengeluaran dan pemasukan yang telah didiskon dengan menggunakan social opportunity cost of capital sebagai diskon faktor, atau dengan kata lain merupakan arus kas yang diperkirakan pada masa yang akan datang yang didiskonkan pada saat ini. Untuk menghitung NPV diperlukan data tentang perkiraan biaya investasi, biaya operasi, dan pemeliharaan serta perkiraan manfaat/benefit dari proyek yang direncanakan.

\section{Sampel}

Ada beberapa pengertian sampel, yaitu: Sampel secara sederhana diartikan sebagai bagian dari populasi yang menjadi sumber data sebenarnya dalam suatu penelitian. Artinya sampel adalah sebagian dari populasi untuk mewakili seluruh populasi (Nawawi, 1983). Sampel adalah sebagian individu yang diselidiki (Soetrisno Hadi, 1983). Sampel adalah sebagian dari populasi yang karakteristiknya hendak diselidiki. Sampel dalam penelitian ini adalah Warnet Bulian City Net Muara Bulian

\section{Teknik Pengambilan Sampel}

Sampling adalah cara untuk menentukan sampel yang jumlahnya sesuai dengan ukuran sampel yang akan dijadikan suber data sebenarnya, dengan memperhatikan sifat dan penyebaran populasi agar diperoleh sampel yang representatif atau benar-benar mewakili populasi (Nawawi, 1983:152). Menentukan sampel sistematis. Penentuan sampel ini merupakan suatu teknik penentuan sampel yang unsur atau anggota pertamanya saja dipilih. Populasi mempunyai pola beraturan seperti blok-blok dalam suatu kotak, atau rumah pada suatu jalan, maka blok-blok atau rumah tersebut dapat diberi nomor urut (Singarimbun, ed., 1983:114-115). Berdasarkan dari pendapat Singarimbun diatas kami sebagai peneliti menganggap teknik pengambilan sampel secara acak sistematis (systematic random sampling) adalah yang paling tepat dalam penelitian yang kami lakukan.

\section{Teknik Pengumpulan Data Observasi}

Observasi merupakan metode yang pertama kali digunakan dalam penelitian ilmiah, dimana penelitian dapat secara langsung mengetahui sasaran yang akan diteliti. Dalam hal ini penulis menentukan elemen-elemen utama yang menjadi sasaran dari pengamatan. Penelitian ini memakai observasi tak tersturktur, yaitu tidak mempersiapkan panduan secara baku tetapi akan mengembangkan fokus observasi pada waktu kegiatan penelitian berlangsung.

\section{Wawancara}

Wawancara merupakan cara utama untuk mengumpulkan data atau informasi dalam penelitian kualitatif, dimana peneliti ingin mendapatkannya secara lisan dari responden. Dalam penelitian ini, menggunakan media angket 
untuk mempermudah dalam penelitian dengan pertanyaan dan jawaban alternatif yang sudah dipersiapkan sebelumnya.

\section{Angket}

Warnet Bulian City Net Buka setiap harinya 14 Jam, yang dibuka mulai dari jam 07.00-21.00 warnet cepat ditutup karena operator yang bekerja adalah wanita. Ruang Komputer yang dimiliki Bulian City net ini ada 8 Ruang computer belum termasuk 2 komputer Operator. Jadi jumlahkeseluruhankomputer yang dimiliki warnet ini ada 10 buah. Tarif yang dikenakan dalam permainan warnet ini seperti warnet lain pada umumnya yaitu 1 jam dikenakan tarif 30002 jam 5.0003 Jam 8.000. waret ini juga menerima jasa Print selembarnya hitam putih 350 . Untuk print warna memiliki harga yang berbeda tergantung warna yang akan dicetak. Dalam hal ini warnet dapat menghasilkan rata- rata 300.000/ hari. Bulian City Net menggaji karyawan sebesar 600.000/Bulannya dengan cara perhitungan gaji karyawan satu jam 2.000. pada umumnya yang banyak mendatangi warnet ini adalah Anak sekolah dan Mahasiswa. Karena tempat nya cukup dekat dengan Kampus yang ada.

Klien menggunakan jasa warnet bervariasi lanya. Biasanya banyak yang memainkan dalam waktu 2 jam. Akan tetapi tidak sedikit juga yang menggunakan warnet dalam waktu singkat missal nya 19 menit, itu dikenakan tarif 1.000. mereka yang datang biasanya banyak mengunjungi situs Facebook, serta situs Pendidikan. Seiring banyaknya area hotspot/wifi tidak berdampak berkurangnya klien warnet. Karena kebanyakan mereka membutuhkan hal-hal yang instan, tetapi tidak memiliki perlengkapan untuk membuat, misalnya para mahasiswa diberikan tugas oleh dosennya. Akan tetapi mereka tidak memiliki laptop. Alhasil pasti akan berkunjung ke warnet serta ingin hal yang instan yaitu copy paste.

\section{HASIL}

Usaha warnet disekitar Sekolah Tinggi Agama Islam hanya berjumlah 5 (lima), maka sebagai peneliti hanya melakukan 1 sampel sebagai penelitian. Hasil angket yang telah dibuat, sebagai berikut:

1. Operator warnet mengemukakan bahwa, banyaknya area Wi-Fi dan semakin bertambahnya pengguna laptop/komputer pribadi, tidak mengurangi omset pendapatan usaha mereka.

2. Rata-rata penghasilan usaha warnet setiap harinya adalah Rp. $200.000-\mathrm{Rp}$. 500.000 .

3. Klien/pengguna jasa kebanyakan adalah Mahasiswa.

4. Kebanyakan para klien, menggunakan internet untuk membuka situs jejaring sosial dalam hal ini Facebook serta Pendidikan(4 dari 5 warnet menjawab seperti itu).

5. Operator warnet mengungkapkan penghasilan menurun pada waktu mahasiswa Sekolah Tinggi Agama Islam sedang libur.

Usaha warnet adalah salah satu pilihan bisnis yang masih menjanjikan saat ini. Internet sudah menjadi satu kebutuhan yang tidak bisa dipungkiri lagi terutama bagi pelajar dan usahawan. Di era modern seperti sekarang ini internet sebagai pilihan terbaik untuk menunjang semua kebutuhan seperti; bisnis, pekerjaan, dan bahkan hobby. Maka dari itu, bisnis jasa penyedia koneksi internet ialah warnet akan tetap dibutuhkan di masa-masa mendatang. Sebelumnya kami kira dengan adanya area hostpot/ Wi-Fi, modem murah, netbook murah dan 
ketatnya persaingan usaha yang sama, akan menghambat usaha warnet ternyata pendapat kami tidak sepenuhnya benar.

\section{Aspek Legalitas Dan Yuridis}

Agar tidak terjadi yang tidak diinginka dikemudian hari maka usaha ini akan dilengkapi dengan berbagai legalitas dalam pendirian usaha ini. Tujuannya adalah jika terjadi permasalahan-permasalahan di belakang hari maka bukti hokum ini bisa dipertanggungjawabkan. Adapun legalitas usaha yang kami lengkapi adalah sebagai berikut :

1. NPWP (Nomor Pokok Wajib Pajak) adalah nomor yang diberikan kepada wajib pajak (WP) sebagai sarana dalam administrasi perpajakan yang dipergunakan sebagai tanda pengenal diri atau identitas wajib pajak dalam melaksanakan hak dan kewajiban perpajakannya. Adapun nomor wajib pajak usaha kami adalah 2.0004572.03.02

2. SIUP (Surat Izin Usaha Perdagangan)

3. IMB (Izin Mendirikan Bangunan)

4. Izin Domisili

5. Bukti Diri Kepemilikan Usaha

\section{Aspek Pasar Dan Pemasaran}

1. Gambaran Umum Pasar

Jenis produk atau jasa yang kami sediakan di warnet ini adalah berbagai macam game online mulai dari yang terbaru sampai yang sudah klasik. Kami juga menyediakan percetqakan/ Print serta Cetak poto yang berfungsi memudahkan para Mahasiswa/mahasiswi dalam mencetak tugas mereka.

2. Permintaan

a. Sasaran membuka warnet ini adalah untuk menarik para pelanggan yang gemar bermain game terutama para remaja, selain itu kami juga menarik para mahasiswa yang ingin mencari tugas kuliahnya dan masih banyak lagi target-target lainnya.

b. Kami asumsikan bahwa penghasilan perhari sekitar Rp 3.00.000, jika sebulan diperkirakan mendapat penghasilan kotor adalah sebesar Rp 9.000.000,- dan dalam setahun dapat menghasilkan laba kotor sebesar Rp 108.000.000,-

3. Strategi Pemasaran

a. Produk, produk atau jasa yang kami sediakan adalah berbagai game online, browsing, chatting, jasa pengetikkan, dan print.

b. Harga, masalah harga kami masih sama dengan warnet lainya yaitu $\mathrm{Rp}$ 3.000 per jam, Rp. 5.000 per dua jam, Rp. 8.000 per tiga jam, Rp. 10.000 per 5 jam

c. Jalur penjualan/tempat, dalam masalah tempat kami berlokasi di Simpang Koni RT.17 Kel. Teratai merupakan tempat yang strategi. Strateginya adalah dekat dengan kos para mahasiswa, perumahan, sekolahan dan kampus.

4. Analisis Pesaing

Berdasarkan survey yang telah kami lakukan bahwa warnet -warnet lainnya tidak menyediakan game online yang terbaru dan Print yang cukup mahal. 


\section{Aspek Teknis Dan Teknologi}

1. Lokasi

Dalam pemilihan lokasi dilakukan survey bahwa lokasi warnet yang dirikan dekat dengan perumahan, daerah keramaian, dan kampus serta kos mahasiswa.

2. Peralatan
a. Komputer Merk LG
b. Link jaringan
c. Kursi Busa/Kursi Putar
d. Meja PC anti kotor
e. Kipas angin, dan lain-lain

\section{Aspek Sumber Daya Manusia}

Dalam penentuan sumber daya insani kami hanya membututkan dua operator. Adapun fungsi karyawan berfungsi untuk menjaga operator warnet dan untuk melayani para pelanggan.

\section{Aspek Keuangan}

\section{Modal Awal}

\begin{tabular}{|c|c|c|c|c|}
\hline No & Uraian & Unit & Satuan & Total \\
\hline 1 & Sewa Gedung/Ruko & 1 Tahun & 10.000 .000 & 10.000 .000 \\
\hline 2 & Komputer & 10 & 5.000 .000 & 50.000 .000 \\
\hline 3 & Meja PC dan kursi & 10 & 1.000 .000 & 12.000 .000 \\
\hline 4 & Jaringan & 1 & 3.000 .000 & 2.000 .000 \\
\hline 5 & Server & 1 & 3.000 .000 & 8.000 .000 \\
\hline 6 & Biaya Lain-lain & 1 & 2.000 .000 & 15.000 .000 \\
\hline \multicolumn{4}{|c|}{ Total } & 100.000 .000 \\
\hline
\end{tabular}

Sumber: Warnet Bulian City Net Muara Bulian.

\section{Aliran Kas Bersih (Net Cash Flow)}

Netto perhari rata-rata Rp. 300.000

Pendapatan perbulan Rp. $300.000 \times 30$ hari $=9.000 .000$

Pendapatan pertahun Rp. 9.000.000 X 12 bulan $=108.000 .000$

Nilai Residu $=$ Modal : 4

Penyusutan $=\underline{\text { Harga Perolehan-Nilai Residu }}$

$$
\begin{aligned}
& =\frac{100.000 .000-25.000 .000}{3 \text { tahun }} \\
& =25.000 .000
\end{aligned}
$$

\begin{tabular}{|c|c|c|}
\hline \multicolumn{2}{|l|}{ Penghasilan } & 108.000 .000 \\
\hline Biaya Tunai & 100.000 .000 & \\
\hline Penyusutan & 25.000 .000 & \\
\hline & & 75.000 .000 \\
\hline Laba Sebelum pajak (EBT) & & 33.000 .000 \\
\hline Pajak (10\%) & & $\underline{3.300 .000}$ \\
\hline Laba Setelah Pajak (EAT) & & 29.700 .000 \\
\hline
\end{tabular}

\section{Uraian Proyeksi laba/rugi pertahun pertama}

Sumber: Warnet Bulian City Net Muara Bulian. 
Maka aliran kas masuk $=$ EAT + Penyusutan

$$
\begin{aligned}
& =29.700 .000+25.000 .000 \\
& =54.700 .000
\end{aligned}
$$

\section{Analisis Kelayakan Investasi}

1) Payback Period (PP)

$$
\begin{aligned}
\text { Payback Period } & =\frac{\text { Investasi kas bersih }}{\text { Aliran kas masukbersih tahunan }} \\
& =\frac{100.000 .000}{54.700 .000} \\
& =1.828
\end{aligned}
$$

$-0.828 \times 365=302.22$ hari

$-302.22 \times 30 \quad=9.066$ bulan

$-0.066 \times 30=1.98$ hari dibulatkan 2 hari

Jadi, dana yang di investasikan Rp. 100.000.000 akan kembali seluruhnya setelah beropersi selama 1 tahun 9 bulan 2 hari.

2) Net Present Value (NPV)

$\mathrm{NPV}=\frac{\mathrm{PV}}{(1+\mathrm{r})}+\frac{\mathrm{PV}}{(1+\mathrm{r})^{2}}+\frac{\mathrm{PV}}{(1+\mathrm{r})^{3}}+\frac{\mathrm{PV}}{(1+\mathrm{r})^{4}}+\frac{\mathrm{PV} \mathrm{N}}{(1+\mathrm{r})^{\mathrm{n}}}$

\begin{tabular}{llll}
\hline Tahun & \multicolumn{1}{c}{ Kas Bersih } & \multicolumn{1}{c}{ DF (10\%) } & \multicolumn{1}{c}{ PV Kas Bersih } \\
\hline 1 & 29.700 .000 & 0.9 & 26.730 .000 \\
2 & 29.700 .000 & 0.8 & 23.760 .000 \\
3 & 29.700 .000 & 0.7 & 20.790 .000 \\
4 & 29.700 .000 & 0.65 & 19.305 .000 \\
5 & 29.700 .000 & 0.6 & 17.820 .000
\end{tabular}

Total PV kas bersih $\quad 108.405 .000$

\begin{tabular}{ll}
\hline Total PV kas bersih & $=\mathbf{1 0 8 . 4 0 5 . 0 0 0}$ \\
Total PV Investasi & $=\underline{\mathbf{1 0 0 . 0 0 0 . 0 0 0}-}$ \\
NPV & $=\mathbf{8 . 4 0 5 . 0 0 0}$
\end{tabular}

dijalankan.

Jadi, karena nilai NPV usaha warnet ini positif maka usaha ini layak untuk

\section{SIMPULAN}

Usaha warnet adalah salah satu pilihan bisnis yang masih menjanjikan saat ini. Internet sudah menjadi satu kebutuhan yang tidak bisa dipungkiri lagi terutama bagi pelajar dan usahawan, yang selalu membutuhkan informasiinformasi yang mereka butuhkan dengan instan tanpa harus ke perpustakaan (sebagai referensi) atau bertemu secara langsung dengan relasi mereka. Meski usaha dibidang jasa warnet memiliki banyak kendala dan saingan yang cukup banyak, ternyata usaha ini masih cukup menjajikan sekarang ini. Kendala usaha warnet seperti; hostpot/ Wi-Fi, netbook murah, cybercafé, global internet, semakin banyaknya pengguna laptop/computer pribadi dan banyaknya usaha serupa. Kendala-kendala tersebut tidak menpengaruhi berjalannya usaha ini secara signifikan. Secara psikologis bagi karyawan/operator warnet adalah timbulnya rasa jenuh dan bosan karena berdiam diri disatu tempat saja setiap harinya. 


\section{DAFTAR PUSTAKA}

Arthur J. Keown, John D. Martin, J. William Petty, David E Scott, Jr. , Financial Management: Principles and Applications, Ninth Edition, Printice-Hall, 2002

Cristofel. 2012. IRR dan NPV. http://christofelsualang.blogspot.com/. Diakses tanggal 02 Januari 2014

http://bisnisukm.com/membangun-usaha-warnet-yang-kompetitif.html

http://dendi.conceptforum.net/t9p30-kewirausahaan-konsep-usaha

http://gaganet01.blogspot.com/2010/04/pengertian-warnet.html

http://niluhputunitaa.blogspot.com/2013/11/proposal-pendirian-usaha-warnet.html http://wirausahawirausaha.blogspot.com/2012/05/suka-duka-usaha-warnet.html http://www.simpang3iga.com/2013/10/langkah-langkah-awal-mendirikan-usahawarnet-game-online.html

Kasmir dan Jakfar. Studi Kelayakan Bisnis. Edisi Kedua. Jakarta: Kencana Prenada Media Group, 2008.

Philip Kotler, Marketing Management : Analysis, Planning, Implementation, and Control, Eleventh Edition, PrinticeHall, 2003

Rechard A. Brealey, Stewart C. Myers, Principles of Corporate Finance, Fourth Edition, McGraw-Hill, 1991

Suliyanto. 2010. Studi Kelayakan Bisnis Pendekatan Praktis. Yogyakarta : Andi Offset.

Sunarya, Abas et al, 2011, Kewirausahaan. Andi: Yogyakarta 